\title{
Humanistic dimensions of professionalism in the practice of neurology
}

\author{
American Academy of Neurology Ethics, Law, and Humanities Committee
}

When neurologists are asked why they chose neurology as their profession, reasons commonly heard include a fascination with neuroscience and clinical neurology and a strong personal commitment to caring for individuals with neurologic disorders. Unfortunately, rapid, market-driven changes in the health care environment have led many neurologists to believe that financial and time pressures on practice are eroding the quality and traditions of neurologic care and draining the personal fulfillment and satisfaction out of clinical neurology. ${ }^{1}$

It is no longer enough to keep up with advances in neuroscience and clinical neurology. Neurologists must review and integrate emerging practice guidelines, laws, regulations, and insurance rules. Nonmedical considerations intrude increasingly upon clinical time and threaten unhurried, attentive, concerned listening, examining, and counseling. Documentation consumes time that patients expect will be devoted to their needs. The result is an unspoken conflict between patients and physicians over time utilization. From the patient's perspective, the overall quality of the neurologic care provided in the time available depends upon its humanistic character. From the neurologist's perspective, commercial interests in medicine do not value traditional aspects of caring that are based on ethical duties of physicians to patients.

Medicine is both art and science. The humanistic core of medicine involves the art of listening, empathy, communication, and other interpersonal interactions that are as essential to good clinical neurology as its scientific foundation. Each neurologist should regularly and conscientiously consider the relationship between practice policies adopted to accommodate managed care and the fiduciary duty of every physician to place patient interests first. ${ }^{2}$

The American Academy of Neurology (AAN) supports health care reform that creates conditions fa- vorable to humanistic care by restoring decision making to the physician and patient. At the same time, the AAN recognizes that the ethical responsibilities of neurologists to patients are not contingent upon reform and are most important when conditions are most unfavorable. Therefore, the AAN issues this call to professionalism and encourages neurologists to nurture the humanistic heart of the physician-patient relationship.

To encourage neurologists to resolve time pressures in their patients' favor, and to help dispel the false and destructive notion that humanistic practices are now expendable inefficiencies, the AAN Ethics, Law, and Humanities Committee here summarizes humanistic professional attributes we consider intrinsic to good neurologic practice. These values are consistent with recent literature that stresses the importance of ethical reasoning to resolve conflicts of interest and obligation under managed care, ${ }^{3-6}$ to meet society's demand that medicine must restore personalized care,${ }^{7}$ and to highlight the vital role of the character of the physician in establishing trust in the physician-patient relationship. ${ }^{8,9}$ The following list is not meant to be exhaustive, and is offered respectfully to stimulate reflection and discussion.

1. Developing an understanding of the complex and elegant workings of the human nervous system in health and disease. The neurologist appreciates the importance of brain development, maturation, and impairment in defining our thoughts, perceptions, accomplishments, and humanity, and of the peripheral nervous system in realizing them. The neurologist understands that there is no animal or other experimental model outside the clinical setting for study of phenomena inseparable from the "person," such as human language, behavior, and consciousness. 
2. Striving to stay abreast of the rapid changes and advances in neuroscience, evidence-based clinical neurology, and ethics through rigorous continuing education. This professional commitment fosters state-of-the-art care for patients with neurologic diseases.

3. Appreciating the necessity to approach the whole patient, rather than focus exclusively on what ostensibly is the "presenting" problem. If the neurologist succeeds in this approach, the patient will see the neurologist as not only a specialist in diseases of the nervous system, but also a complete physician.

4. Recognizing that understanding the patient's narrative - as told by the patient or, if necessary, by others-is essential to successful treatment. The neurologist should strive to understand the inner experience of patients, the meanings they attach to illness, and their personal values..$^{10}$ The neurologist must be alert for nuance while taking the patient's history to grasp what is really being said and sought by the patient. Standard history forms and checklists should be set aside when they impede rather than facilitate patient expression. Humanistic insights guide decisions along lines that respect the autonomy of patients and enable them to share in decision making. Since Hippocrates, the narrative has been the foundation for both the physicianpatient privilege and also the special privilege it is to be a physician. The narrative does not reduce each neurologist's responsibility to learn ethical principles. It is the best framework for their application.

5. Appreciating that a precise and detailed neurologic examination personally performed can create a strong bond between patient and doctor. The neurologist must observe and carefully examine each patient to understand the specific problems clearly. While many elements of the examination can be quantified and analyzed away from the patient, it is the hands-on quality of this data gathering that establishes a seamless transition between diagnosis and effective treatment. It ensures that MRI and other technical devices are merely tools, not solutions.

6. Remaining sensitive to the perceptions of neurologic disorders that exist in the minds of patients and their families. Patients and families often respond with dread and a sense of helplessness to the disability produced by these disorders, and their uncertain implications for the future. The neurologist develops a perspective on neurologic disorders that differs from the view of the general public, and also of physicians who do not specialize in diseases of the nervous system. The neurologist's thorough understanding of the signs and symptoms of neurologic disorders, even those that seem grotesque or terrifying to patients and families, transforms a potential barrier into a bridge to the physician-patient relationship.

7. Accepting the obligation to gain experience in order to justify a confident approach that will support patient and family. The neurologist knows the crucial importance of translating highly complex scientific concepts and medical data into plain language that patients and families can understand. When in doubt, the neurologist should have the humility to obtain help through appropriate consultations.

8. Understanding the need to develop a sense of when to perform potentially distressing diagnostic tests such as genetic analyses, and when to broach frightening and emotional subjects related to patient care. This includes the ability to help patients anticipate the future without undermining hope. ${ }^{11}$

9. Maintaining a commitment to treat patients with chronic, sometimes intractable conditions. Skilled pharmacotherapy and appropriate use of ancillary services are necessary, but are not sufficient for optimal care and function of patients with migraine, epilepsy, stroke, traumatic injury of the brain and spinal cord, multiple sclerosis, AD, PD, ALS, ${ }^{12}$ MG, neuropathy, chronic pain, and other disorders. They require a faithful partnership, so the patient need never fear abandonment.

10. Understanding that neurologists should play a pivotal role in defining and administering highquality palliative and end-of-life care. ${ }^{13}$ The neurologist cares regularly for patients for whom comfort care and end-of-life decisions are foreseeable or at hand. The neurologist should encourage patients well before terminal illness to execute advance directives to clarify their wishes about future lifesustaining treatment, and help the families of critically ill patients align treatment with prognosis and the patient's values.

To use these professional attributes successfully in treating neurologic patients, the neurologist should also strive to develop certain personal virtues. These include prudence, intelligence, creativity, diligence, honesty, compassion, respect, sensitivity, optimism, consistency, and the ability to recognize and remedy personal shortcomings. However, virtuous character is not sufficient. These virtues must be coupled in neurologic practice with a working knowledge of principles of medical ethics and ethical reasoning. ${ }^{14}$ The neurologist who is not humble, even at the moment of triumph over a challenging medical problem, has allowed hubris to undermine professional responsibility to patient. Ideally, the neurologist who strives to integrate sound science with humanistic professional attributes and personal virtues will experience satisfaction in advancing the cause of optimal patient care.

\section{Appendix}

Ethics, Law, and Humanities Subcommittee Members: Glenn A. Mackin, MD (Principal Author), Lehigh Valley Hospital, Allentown, PA; H. Richard Beresford, MD, JD, University of Rochester, NY, and Cornell Law School, Ithaca, NY; James L. Bernat, MD, Dartmouth Hitchcock Medical Center, Lebanon, NH; David Goldblatt, MD, University of Rochester, NY; Michael P. McQuillen, MD, University of Rochester, NY; Lois M. Nora, MD, JD, University of Kentucky, Lexington; Russell D. Snyder, Jr., MD, University of New Mexico, Albuquerque; and Robert M. Taylor, MD, Mt. Carmel East Hospital, Columbus, OH. 


\section{References}

1. Bernat JL, Ringel SP, Vickrey BG, Keran C. Attitudes of US neurologists concerning the ethical dimensions of managed care. Neurology 1997;49:4-13.

2. Pellegrino ED, Thomasma DC. For the patient's good: the restoration of beneficence in health care. New York, NY: Oxford University Press, 1988.

3. The Ethics and Humanities Subcommittee of the Practice Committee of the American Academy of Neurology. Managed care and neurologists. Neurology 1997;49:321-322.

4. McQuillen MP. Values in conflict: neurology before and after the advent of managed care. Semin Neurol 1997;17:281-285.

5. Kassirer JP. Managed care-should we adopt a new ethic? N Engl J Med 1998;339:397-398.

6. Bernat JL, Goldstein ML, Ringel SP. Conflicts of interest in neurology. Neurology 1998;50:327-331.

7. Brinkley A. Faiths that failed? Professionalism, technology, and science in 20th century America. Neurology 1998;51:651661.
8. Pellegrino ED, Thomasma DC. The virtues in medical practice. New York, NY: Oxford University Press, 1993.

9. Rosenow EC. The challenge of becoming a distinguished clinician. Mayo Clin Proc 1999;74:635-640.

10. Sacks O. The man who mistook his wife for a hat and other clinical tales. New York, NY: Summit Books, 1985, xiv.

11. Ptacek JT, Eberhardt TL. Breaking bad news: a review of the literature. JAMA 1996;276:496-502.

12. Miller RG, Rosenberg JA, Gelinas DF, et al., and the ALS Practice Parameters Task Force. Practice parameter: the care of the patient with amyotrophic lateral sclerosis (an evidencebased review). Report of the Quality Standards Subcommittee of the American Academy of Neurology. Neurology 1999;52: 1311-1323.

13. The American Academy of Neurology Ethics and Humanities Subcommittee. Palliative care in neurology. Neurology 1996; 46:870-872.

14. Bernat JL. Ethical issues in neurology. Boston, MA: Butterworth-Heinemann, 1994. 


\section{Neurology}

\section{Humanistic dimensions of professionalism in the practice of neurology}

American Academy of Neurology Ethics, Law, and Humanities Committee

Neurology 2001;56;1261-1263

DOI 10.1212/WNL.56.10.1261

\section{This information is current as of May 22, 2001}

Updated Information \&

Services

References

Citations

Permissions \& Licensing

Reprints including high resolution figures, can be found at: http://n.neurology.org/content/56/10/1261.full

This article cites 9 articles, 4 of which you can access for free at: http://n.neurology.org/content/56/10/1261.full\#ref-list-1

This article has been cited by 2 HighWire-hosted articles: http://n.neurology.org/content/56/10/1261.full\#\#otherarticles

Information about reproducing this article in parts (figures,tables) or in its entirety can be found online at:

http://www.neurology.org/about/about_the_journal\#permissions

Information about ordering reprints can be found online:

http://n.neurology.org/subscribers/advertise

Neurology ${ }^{\circledR}$ is the official journal of the American Academy of Neurology. Published continuously since 1951, it is now a weekly with 48 issues per year. Copyright. All rights reserved. Print ISSN: 0028-3878. Online ISSN: 1526-632X.

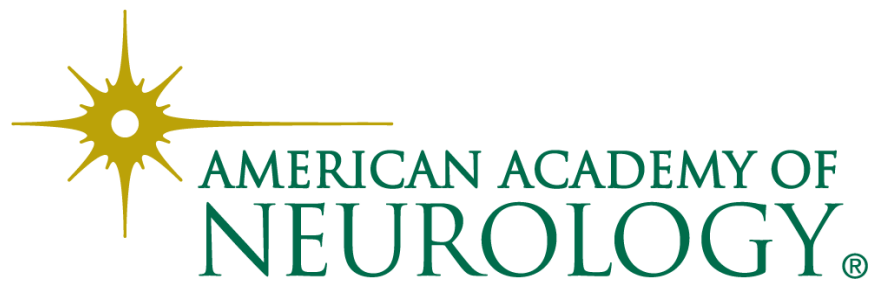

